\title{
Quest for a Hockey Franchise
}

\author{
Alex Faseruk \\ Memorial University of Newfoundland \\ Tom Clift \\ Memorial University of Newfoundland
}

This study documents the history of attracting and maintaining a hockey franchise for the City of St. John's, Newfoundland and Labrador from 1991-2019. In that period, the City has been granted four

franchises. Three have been relocated, while the fourth has completed its inaugural season which resulted in a league championship. It examines: the St. John's Maple Leafs (1991-2005) of the American Hockey League (AHL); St. John's Fog Devils of the Quebec Major Junior Hockey League (QMJHL) (2005-2008); the St. John's IceCaps (AHL), affiliated with the Winnipeg Jets (2011-2015) and Montreal Canadiens 2015-2017); and the Newfoundland Growlers in the ECHL, (2018-ongoing). The study focuses on the economic, marketing, strategic planning, and business modelling for a hockey franchise in three hockey leagues, AHL, QMJHL, and ECHL to gauge the long-term sustainability of a hockey franchise in St. John's. It analyzes key success factors for minor league hockey franchises and speculates on the future direction of the current franchise.

Keywords: minor league, franchise, ice hockey, economic viability

\section{INTRODUCTION}

The 1981 Franco-Canadian science fantasy adventure movie Quest for Fire was set in Paleolithic Europe, approximately 80,000 years ago. The movie focuses on three members of a tribe who set out on a quest to find fire. Their village's fire was extinguished and the tribe does not know how to rekindle a fire. The film deals with the trials, tribulations and battles during these exploits. Eventually, they succeed in bringing fire back to the village. The film was a success critically and at the box office. Quest for Fire won two César awards in France, five Genies in Canada, and the Academy Award for Makeup. Roger Ebert gave the film $3 \frac{1}{2}$ stars out of four. The film grossed $\$ 55$ million from a budget of $\$ 12$ million. By all measures their quest was a success. For St. John's, Newfoundland and Labrador, the quest for a successful hockey franchise is still ongoing. The trials and tribulations, as well as the inevitable battles, continue.

St. John's has been awarded four franchises in three hockey leagues; one has just completed its first year of operation. One failed outright and was relocated. Two other successful franchises have been relocated by their NHL parents. This study documents the history of the quest for a hockey franchise for St. John's from 1991-2019, showing how three franchises have left St. John's, with the fourth having just 
completed its inaugural season in 2018-19. In fact, the nascent team won the ECHL Championship and was awarded the Kelly Cup.

In undertaking this study, specific attention is paid to the business/economic modelling, strategic planning, on ice and financial success of the various franchises. References are also made to several personalities associated with either the various parent clubs or local people in the franchise. Not all the people are named in order to respect the right to privacy for information not in the public domain. The authors also disclose that they have at many points over the 1991-2019 period been involved with some of the decision-making boards. Confidentiality is observed and only items in the public domain are referenced.

This study consists of six sections. In the first section, the pre-1991 franchises of the Toronto Maple Leafs are examined to understand the circumstances surrounding the decision in 1991 to relocate the franchise to St. John's. The second section deals with a history of the successes and problems associated with the establishment of the first franchise in St. John's, the St. John's Maple Leafs, in the American Hockey League, AHL, and the primary player development league of the NHL. The third section deals with the ill-fated and least successful franchise, the St. John's Fog Devils in the Quebec Major Junior Hockey League (QMJHL). The fourth section documents the return of the AHL to the city as the St. John's IceCaps, initially affiliated with the Winnipeg Jets of the NHL and later affiliated with the storied Montreal Canadiens. The fifth section deals with the fourth and current hockey franchise, the Newfoundland Growlers of the ECHL. The sixth section concludes the study, highlights summary findings and addresses certain key considerations, which potential franchisees might consider when establishing a minor league sports franchise in their area in a different quest for a hockey franchise.

\section{PRE-1991 FRANCHISES OF THE TORONTO MAPLE LEAFS}

In 1991, the St. John's Maple Leafs (SJML) became the primary AHL player development (farm) team for the parent club, the Toronto Maple Leafs (the Leafs) of the NHL. The Leafs farm relocated the team from Ontario.

The AHL is a professional ice hockey league primarily based in the United States, but also in Canada. Of the 31 AHL teams, 27 are in the United States with four in Canada. For more than 75 years, the AHL has served as the primary developmental league for the NHL. Since 2010-11, every team in the AHL has had an affiliation with a single NHL team. When NHL teams do not have an AHL affiliate, players are assigned to AHL teams affiliated with other NHL teams. In 1994, when its rival development league, the International Hockey league (IHL), a league which used older more experienced players, was experiencing financial trouble, the AHL embarked upon a strategic planning process to fully reposition itself as the primary development league of younger professional hockey players. These players must be at least 18 years old. The league limited the number of players who had accumulated four full seasons of play at the professional level to five skaters per team. In 2001, the IHL folded. The AHL and NHL work closely to ensure that players are developed in a manner closely resembling the NHL.

Like the NHL, the AHL has a four-series playoff format. AHL teams compete for the Calder Cup, named for Frank Calder, the first President of the NHL (1917-1943). The NHL awards the Stanley Cup, first won by Toronto (Toronto Arenas) in the NHL's inaugural season 1917-18. Toronto last won the Stanley Cup in 1967. The current AHL team of the Leafs, the Toronto Marlies, won the Calder Cup in 2018.

The most recent version of the Leafs' farm team in the AHL began in 1978 as the New Brunswick Hawks, playing their games in Moncton, NB. The Hawks were not the first AHL franchise for the Leafs. Their first was the Rochester Americans, which entered the AHL for the 1956-57 season. It was a joint affiliate of the Montreal Canadiens and the Leafs. Each NHL club owned 27.5\% of the shares, with the remaining 45\% held by Rochester-area investors. In summer 1959, the Leafs bought out the Canadiens' share. They felt that with Montreal operating the club, they were giving their prospects priority over those of the Leafs. In 1963 the Leafs purchased most of the remaining outstanding shares for a 98\% stake. 
The Rochester franchise proved to be successful for the Leafs following the divestiture by the Canadiens. Rochester captured the Calder Cup in 1965, 1966, and 1968, with runner up in 1967. They are the only AHL team to have appeared in four consecutive Calder Cup finals. Following the expansion of the NHL from six teams to 12 teams for the 1967-68 season, the fortunes changed.

In July 1966, the Leafs sold their AHL team to a group, which included George "Punch" Imlach, then the General Manager of the Leafs, for $\$ 400,000$. Two years later the team was sold to the Vancouver Canucks of the Western Hockey League (WHL) for $\$ 950,000$. Imlach was an owner of the Canucks at the time. He was fired from the Leafs in 1969, after failing to make the playoffs in 1968 and an embarrassing loss to Boston in the 1969 playoffs. Imlach had reached six Stanley Cup finals and won four during his tenure as coach. The Leafs continued to use Rochester as an affiliate through the 1968-69 season, but relinquished the affiliation following the sale to Vancouver. The Leafs were left without a minor league affiliate and several of the star players of the Leafs were traded away by Imlach. The Vancouver Canucks were sold for \$2.8 million and subsequently entered the NHL in 1970. The Canucks retained the Rochester Americans as their farm team.

From 1968-69 to 1977-78, the Leafs did not have a farm system. They relied heavily on placing their drafted players with other affiliates. However, after years of poor draft picks and insufficient control over the player development in these affiliated teams, the Leafs founded the New Brunswick Hawks. The various AHL affiliates for the Leafs have been:

- 1978-1982 New Brunswick Hawks

- 1982-1986 St. Catharines Saints

- 1986-1991 Newmarket Saints

- 1991-2005 St. John's Maple Leafs

- 2005 Toronto Marlies

The New Brunswick Hawks were established as a joint AHL affiliate for the Chicago Black Hawks and the Leafs. The team had a winning record for all the seasons when they played in New Brunswick. They won the F. G. (Teddy) Oke Trophy for regular season division champions in 1979-80 and 1981-82. The Hawks won the Calder Cup in 1982. In 1980, despite the on-ice success, Harold Ballard, the owner of the Leafs, had decided that they required a stand-alone developmental team. In 1981, Maple Leafs Gardens Limited (MLGL) launched the Cincinnati Tigers in the Central Hockey League as a Leafs' affiliate, while retaining their share of the New Brunswick Hawks. The Tigers averaged only 1,500 fans per game and lost $\$ 750,000$ in their first year. MLGL folded the team after one season.

During the summer of 1982, the Chicago Black Hawks pulled out of the joint management relationship in Moncton and became affiliated with the Springfield Indians as a standalone operation. The Leafs negotiated with Moncton, but could not come to terms for a new arena lease. Instead they relocated the team to the Ontario market, despite having the fifth highest attendance in the AHL.

The Leafs wanted to relocate the team closer to Toronto. Both St. Catharines and Niagara Falls were considered as potential locations. Both these cities at one point had highly successful Junior A/Major Junior A teams in the former Ontario Hockey Association (OHA) or the current Ontario Hockey League (OHL). With reduced travel costs between the parent club and the farm team, it was felt that either location would be lucrative for the Leafs.

When MLGL applied to the AHL in 1982 to relocate the New Brunswick Hawks to St. Catharines, the Buffalo Sabres objected as St. Catharines was far closer to Buffalo than Toronto. The Leafs had not consulted with the Sabres prior to the application. However, following protests by the St. Catharines fans and threats by Ballard to simply suspend the Moncton franchise to prevent another AHL franchise from relocating to the city, as well as threatening to sue the Sabres for \$20 million, the relocation was approved unanimously by the AHL Board of Directors. The new franchise was named the St. Catharines Saints. At that same meeting, the Edmonton Oilers were awarded a new AHL franchise for Moncton, which became known as the Moncton Alpines.

The Sabres, in challenging Ballard's plans to put an AHL franchise in St. Catharines, faced a very daunting task. Ballard had long been associated with hockey. He had been an assistant manager for the 
Canadian gold medal team at the 1928 Winter Olympics and the coach of the 1933 silver medal team at the World Championships in Prague. The 1933 silver medal was, however, considered a disgrace as it represented the first time that a Canadian team had failed to win the gold medal in either an Olympic or World Championship. The team was involved in several on and off ice fights. Ballard was arrested for fighting in Paris. He was either a coach or a manger with several OHA teams before joining the Leafs in 1940. Initially, he oversaw their minor league affiliates before becoming a member of the executive committee in 1957. With the divestiture of the holdings by Conn Smythe in 1961, Ballard became part of a consortium which included Stafford Smythe (Conn's son) and John Bassett (a media tycoon who became chairman of the board). Ballard had fronted the money, from his family's successful business operations, to Stafford to enable him to buy the shares. Ballard became executive vice president of the Leafs, alternative governor to the NHL and chairman of the team's hockey committee. The Leafs won four Stanley Cups in 1962, 1963, 1964 and 1967.

Ballard, however, showed bellicose behavior in many of business dealings, including fights with the Canadian Broadcasting Company (CBC) about lighting for the color broadcast of the Leafs, selling tickets for two shows for the Beatles when they had contracted for only one, removing a large portrait of the Queen and replacing it with more seats, and being charged, along with Smythe, for tax evasion and using MLGL to pay for personal expenses in 1969. While Bassett had an 8-7 vote to remove them as directors and force them to sell the shares, he did not. A year later, Bassett sold his shares to Ballard and Smythe and exited MLGL. Smythe died just six weeks later. In 1971, Ballard won a legal battle with Smythe's family and was able to buy his shares giving him $60 \%$ control in the Gardens. He became president and chairman of MLGL.

Without outlining all of Ballard's business dealings, suffice it to say that he was very much a handson owner often interfering in the decisions and workings of his coaches and other administrative personnel. Nonetheless, MLGL made record profits year-over-year, while his team generally played poorly. The team has failed to win a Stanley Cup since 1967. However, the fans continue to support the Maple Leafs, selling out virtually every game. Ballard was inducted into the Hockey Hall of Fame in 1997. The Leafs are greatly respected as a senior and founding member of the NHL. In 1982, when the Buffalo Sabres objected to the Leafs' plan to put a franchise in St. Catharines, they were well out of their element as a junior member of the NHL only having a franchise since 1970 and Ballard's tenacity as a negotiator.

While Ballard was known for his charitable activities, he was also known for demeaning treatment of players and coaches, sexist and racist remarks, battling with the media, destruction of historic artifacts and memorabilia (Stanley Cup banners and the historic Gondola), and was charged with domestic assault.

Despite Ballard's behavior, the profits/shares of MLGL continually increased during his tenure. It is, however, worthy of note that when Ballard suffered a heart attack in fall 1986, the shares of MLGL jumped $\$ 5$ when the news was announced to the public. When he died in 1990, there were several court battles over the terms of his will, particularly by his common-law wife, Yolanda, and his three children. Control of MLGL passed to one of the executors of his estate, Steve Stavro. Events such as intervention by Molson Breweries, a court battle with Ballard's son Bill, and an in-depth review of the transactions by the securities commission surrounded the transfer of shares. With Stavro the off-ice drama ceased and standard business modelling became the norm in running the Leafs.

The foregoing discussion has shown that the business decisions to award, move, or revoke franchises can be very capricious, arbitrary, or based on the whims of a franchisor over which the franchisee has little control. Under Ballard, St. John's would not have received the Leafs' AHL franchise and the quest for a hockey franchise would not have been realized.

The Saints played only four seasons in St. Catharines and failed to make the playoffs in two of those years. With dwindling fan support, the franchise was moved to Newmarket, north of Toronto, after the 1986 season. The team retained the Saints name. While this name could be identified with St. Catharines, which had teams in the OHA Senior League in the 1940s and the 1950s named the Saints, the name had little brand recognition in Newmarket. The team lasted there for five years and was only able to make the playoffs once in 1988-89. During their last year, attendance averaged only 1,100. With the poor 
performance of the team and the small arena, the Leafs looked for a new location for their AHL franchise. In May 1991, the AHL Board of Governors approved the move of the team to St. John's.

As is shown in the remainder of this study, the choice of a team name and the design of the team logo are instrumental for the success of a minor league hockey franchise. Without government, corporate, parent club and fan support, a minor league affiliation agreement can be a tenuous process. Once the business model of the parent club and/or the parent league changes, little can be done to alter changes in plans and a new quest would need to be undertaken.

\section{THE ST. JOHN'S MAPLE LEAFS 1991-2005}

The St. John's Maple Leafs (SJML) were established in 1991 when the Leafs moved their AHL franchise from Newmarket. Prior to the move, there had been several rumors that St. John's would receive a franchise. While some discussion focused on the awarding of a new franchise, others thought it would be easier to attempt to transfer an existing franchise. The majority of hockey fans in St. John's at that time were supporters of either the Toronto Maple Leafs or the Montreal Canadiens, with a smaller number cheering for the Boston Bruins. Other NHL teams showed negligible support. Efforts were made to convince one of the more popular NHL teams to relocate to St. John's, as this was considered to be one of the keys to franchise support and stability, something that all team owners strive to achieve.

There are four provinces in Atlantic Canada, Newfoundland and Labrador, Nova Scotia, New Brunswick and Prince Edward Island. Prior to 1991, three other NHL affiliated AHL teams played in the region: the Moncton Hawks (Toronto/Chicago), the Nova Scotia Voyageurs (Montreal) and the Cape Breton Oilers (Edmonton). Atlantic Canada has a strong tradition of knowledgeable hockey fans. With a potentially strong fan-base, local proponents in St. John's felt that a team in St. John's could be a success, both on and off-ice.

In Newfoundland, the love of hockey was deeply rooted. Prior to 1949 (when Newfoundland joined Canada) Foster Hewitt, the original sportscaster of hockey in Canada, used to open his radio broadcasts of the Toronto Maple Leafs hockey games by welcoming fans in Canada, the United States, and Newfoundland. Newfoundland hockey teams had contested for the Herder Memorial Trophy since 1935 and had developed a league and playoff format leading to the award of the trophy. Cup winners were able to compete for the Allan Cup, emblematic of senior hockey supremacy in Canada. When St. John's went in search of an AHL affiliation in 1991, the AHL had been present in the Atlantic Canada market since 1971, when the Nova Scotia Voyageurs in Halifax first began its affiliation with the Montreal Canadiens. With players like Larry Robinson and Steve Shutt, the Vees, (as they were known), became a power house AHL team. They operated successfully in Halifax. From 1971 to 2005, the AHL had franchises in the following Atlantic Canada markets:

- New Brunswick Hawks in Moncton 1978-82

- Fredericton Express 1981-88 (became Halifax Citadels)

- Moncton Alpines 1982-84 (renamed Moncton Golden Flames)

- Nova Scotia Oilers 1984-88 (became Cape Breton Oilers)

- Moncton Golden Flames 1984-87 (folded)

- Moncton Hawks 1987-94 (folded)

- Cape Breton Oilers 1988-96 (became Hamilton Bulldogs)

- Halifax Citadels 1988-93 (became Cornwall Aces)

- Fredericton Canadiens 1990-99 (became the Quebec Citadelles)

- St. John's Maple Leafs 1991-2005 (became the Toronto Marlies)

- Prince Edward Island Senators 1993-96 (became the Binghamton Senators)

- Saint John Flames 1993-2003 (became Omaha Ak-Sar-Ben Knights)

During the business attraction phase, local officials had completed a market potential analysis that indicated interest in an AHL team located in St. John's would be high. Local business people had previously sponsored AHL exhibition games in St. John's during the late 1980s. These games had been 
well attended. Using market factors, outlined below, local officials were confident that approximately 5,000 individuals would be interested in supporting a team under the following assumptions:

1. Consumer interest in professional sports (as defined by the household penetration rate of $15 \%$ ) by The Sports Network, a paid subscription service available in Canada; and

2. Consumers' ability and willingness to pay for a season ticket (estimated as the top $20 \%$ of the income earning population of the St. John's Census Metropolitan Area (SJCMA).

Given $15 \%$ of the target population interested in and willing to pay to watch sports, multiplied by the $20 \%$ of the population that were estimated to be able to afford such an outlay annually, the following estimate was developed. These market factors projected that 3\% (MF1: 15\% $\times$ MF $2.20 \%=3 \%$ ) of the target population or 5,000 individuals $(165,000$ people $\times 3 \%$ combined market factors $=4,950)$ possible season ticket holders (individual or corporate accounts) would constitute sufficient support to justify their investment. The investment would be primarily made by the City of St. John's in the AHL franchise.

With the (then) size of the metropolitan area population base at 165,000 and assuming a similar proportion of the 2,000+ businesses in the area would be interested in acquiring seasons tickets to the City's first minor professional sports team, local proponents appeared optimistic. Actually, local planners underestimated demand. When announced that fans could make a deposit on a pair of season tickets, more than 5,000 requests (for more than 10,000 season tickets) were processed. Given that the stadium that was to house the team could only accommodate 4,200 people (2,400 seats plus standing room), it appeared there would be more than sufficient demand. The price point of the ticket also took into account recovery of costs and to ensure a reasonable return on investment for the City.

On October 19, 1991, the St. John's Maple Leafs, (the AHL affiliate of the Leafs) played their first home game against the Fredericton Canadiens (the AHL affiliate of the Canadiens), a dream match-up, at the sold out St. John's Memorial Stadium. In summer 1991, St. John's City Council had earmarked $\$ 750,000$ in support of renovations to the St. John's Memorial Stadium, an investment that would pay off many times over. In fact, these renovations were recouped in just two years of operation. A two year payback period is very unusual for most capital budgeting projects.

The following table outlines the first 10 years of operation of the SJML. Key considerations when establishing this franchise included: seating capacity; percentage of tickets sold as season tickets; percentage of seating inventory available to occasional fans; and, winning percentage. The last is particularly important as fans generally do not support losing teams in the same way they support winning teams.

\section{TABLE 1}

\begin{tabular}{ccccc}
\hline Year & Won-Loss & Seat $\%$ & \# STH & Profit (Loss) \\
\hline $1991-92$ & 0.575 & $93 \%$ & $900 / 2100$ & $\$ 250,000$ \\
$1992-93$ & 0.610 & $93 \%$ & $900 / 2100$ & $(\$ 620,000)$ \\
$1993-94$ & 0.660 & $93 \%$ & $900 / 2100$ & $\$ 220,000$ \\
$1994-95$ & 0.470 & $91 \%$ & $900 / 2100$ & $(\$ 55,000)$ \\
$1995-96$ & 0.470 & $89 \%$ & $875 / 2100$ & $(\$ 66,000)$ \\
$1996-97$ & 0.514 & $88 \%$ & $875 / 2100$ & $\$ 514,000$ \\
$1997-98$ & 0.400 & $85 \%$ & $825 / 2100$ & $(\$ 44,000)$ \\
$1998-99$ & 0.338 & $84 \%$ & $820 / 2100$ & $(\$ 420,000)$ \\
$1999-2000$ & 0.520 & $93 \%$ & $700 / 2100$ & $\mathrm{n} / \mathrm{a}$ \\
\hline
\end{tabular}

First, the correlation between winning on the ice and winning at the gate is noticeable from casual empiricism. Each year the SJML had a winning record over 0.550 , team profitability exceeded $\$ 200,000$. Second, each year the team winning percentage dropped below 0.400 the team lost a similar or larger amount of money; the lower the winning percentage the more the annual losses mounted. Third, the higher the concentration of tickets in the hands of season ticket holders, the higher the profitability. 
Fourth, the longer an AHL affiliate of an NHL team stays in the same city the more challenging it is to remain profitable: suggesting the presence of a life-cycle for a team in a given city.

So successful was the St. John's franchise that in the late 1990s city officials approved the development of a new downtown stadium and convention facility. It was named Mile One Stadium, as the building was to be located at the eastern-most starting point for the Trans-Canada Highway. In October 2001, Mile One Stadium, with a capacity of 6,287 and 36 corporate boxes/suites, was officially opened.

It is important to note, when documenting additional reasons for the success of this franchise in St. John's, it was the first professional team to come to the City and the province, thereby enjoying the first mover's advantage. However, it is then also important to consider the impact which lower than average competitive intensity may have played in the team's success.

Throughout the 1990s and 2000s the SJML had few, if any, real direct competitors. On some weekend nights, the team faced some competition from local university teams, but for the most part these teams generally drew insufficient (fewer than 1,000 fans most nights) to be considered as direct competitors.

Administratively and legally, while Toronto continued to own the franchise, the City of St. John's incorporated the St. John's Maple Leafs Hockey Club, Inc., which leased the franchise from the Leafs to run the club and remit fees to Toronto in accordance with the lease agreement. Players were under contract to the Toronto parent, but the revenues and expenses were incurred by the SJML. Team salaries and equipment costs were the responsibility of the parent club, while all other expenses, including travel were the responsibility of the AHL team. The team played their home games in Memorial Stadium built in 1954, a city-owned facility, from 1991-2001, when they moved to Mile One Centre, another cityowned facility. They remained there until 2005, when the parent club moved its AHL affiliate to Toronto. This move reflected a change in thinking by many NHL teams.

By 2005, many NHL General Managers saw the potential in having their AHL team co-located in the city of their NHL parent or located within a relatively close proximity, i.e. a driving distance of 200-300 kilometers (120-180 miles) from the respective NHL city. These moves were made to expedite player call-ups from the AHL team to the NHL parent team.

Second, it allowed for closer and timelier oversight of AHL player development, by a wider range of NHL team staff and management, which became increasingly important in the salary cap era.

Third, it facilitated a more effective management of the parent club's salary cap. If a player could be sent down without having to leave town, there were transportation, relocation, and salary dollars to be saved. Consequently, the salary cap could be more successfully administered.

In 2005, the Leafs General Manager John Ferguson relocated the St. John's Maple Leafs to Toronto, to play as the Toronto Marlies in the Ricoh Centre (now the Coca-Cola Coliseum) about $5 \mathrm{~km}$ ( 3 miles) from the Air Canada Centre (now the Scotiabank Arena), home of the Leafs.

It is worth noting that in 2005 less than five AHL affiliate teams were co-located with their NHL parent clubs. By the 2018-19 hockey season, 70\% (21 of 30 NHL parent clubs) were co-located with their AHL development teams.

Having an anchor tenant for a sports complex is important for any franchise to be sustainable either at the Mile One Centre in St. John's or the Ricoh Centre in Toronto to ensure that the sports facility can generate sufficient revenue to cover its capital costs. Consider the Staples Center in Los Angles which currently has as its major tenants, the LA Kings of the NHL, the LA Lakers and Clippers of the NBA, and the LA Sparks of the WNBA.

The SJML were very popular when they were located in the city. This was due in no small part to the fact that during their 14 years in St. John's the team missed the playoffs only three times (2000, 2003, and 2004). In addition, the team had an outstanding inaugural season in making it to the Calder Cup finals, eventually losing 4-3 to the Adirondack Red Wings, the farm team of the Detroit Red Wings. Those two teams had 12 individuals who would go on to highly successful NHL careers, either as players or coaches, including such players as Felix Potvin, Yannick Perrault, Keith Primeau and Bruce Boudreau, and coaches Marc Crawford, Joel Quennville and Barry Melrose. The first two, Crawford and Quennville, won Stanley Cups as coaches, while Melrose coached his team to a Stanley Cup final series. 
On April 29, 2005, the SJML played their final game, game five of the divisional semi-final against the Manitoba Moose at the MTS Centre in Winnipeg, Manitoba. The SJML then became defunct as a hockey team. There are a number of ironies associated with the STML final game against the Manitoba Moose. In 2011, when the NHL's Atlanta Thrashers moved to Winnipeg to become the second incarnation of the Winnipeg Jets, the Manitoba Moose moved to Newfoundland and Labrador to commence play as the St. John's IceCaps. Ironically, the final game for the SJML was the game between the outgoing St. John's team and what would become the future St. John's team.

The relocation of the SJML officially marked the end of 34 consecutive seasons of the AHL in Atlantic Canada, which began with the Nova Scotia Voyageurs in 1971. The parent Leafs wanted to reduce salary and travel costs. By 2003, all other AHL teams in Atlantic Canada (which at one point had six teams and formed an Atlantic Canada Division) had all relocated elsewhere. At that time, the nearest opponent for the SJML was the Portland Pirates 1,781 km (1,107 mi) away.

The Leafs had recently renovated the Ricoh Centre in Toronto in 2005. The cost cutting and potential revenue enhancing strategies resulted in the relocation to Toronto. The team was rebranded as the Marlies, a name which was very recognizable, having been used by Toronto for Junior A/Major Junior A, and senior teams in the past. After the departure of the St. John's IceCaps in 2017, St. John's was awarded an ECHL franchise called the Newfoundland Growlers to begin play in fall 2018. The Growlers became the ECHL affiliate of the Leafs and the Toronto Marlies, returning the presence of the Leafs to St. John's in 2018 after they had left in 2005.

\section{THE ST. JOHN'S FOG DEVILS 2005-08}

Given that there was a tremendous void left in the hockey-loving St. John's by the departure of the SJML in 2005, the Quebec Major Junior Hockey League (QMJHL-referred to as The Q) expanded to St. John's. Simultaneously, the AHL also awarded a franchise to Saint John, NB. The latter also previously had an AHL franchise, the Saint John Flames from 1993-2003 before relocation to Omaha. Not unlike the AHL, the QMJHL either granted new franchises to or relocated teams to Atlantic Canada. These teams are:

- Halifax Mooseheads granted franchise in 1994-present

- Moncton Alpines granted franchise in 1995-switched name to Moncton Wildcats-present

- Cape Breton Screaming Eagles in 1997 following move of Granby Prédateurs-present

- Acadie-Bathurst Titan in 1998 following move of Laval Titan Collège-Français-present

- PEI (Prince Edward Island) Rocket in 2003 following move from Montreal-present

In 2003, the QMJHL adopted a three-division format which had the Atlantic Division consisting of the five teams listed above. It should be noted that the first two teams were playing under the names of popular beers brewed by Moosehead Breweries, with its headquarters in Saint John, NB. The Alpine name, which had also been used in the AHL Moncton franchise in 1982, was dropped in favor of the Wildcats. Despite pressure to change the name from the Mooseheads, the team is still operating as such. There is a tacit agreement that in the future team names will not be named after beer brands. The PEI Rockets changed their name to the Charlottetown Islanders in 2013.

Instead of forming a municipally run corporation to administer the franchise, which was awarded by the QMJHL to St. John's in December 2004, the franchise was put out to tender. The successful bid went to the Dobbin family, a very prominent family in St. John's. Craig Dobbin and Dermot Dobbin provided the capital and Brad Dobbin was responsible for the day-to-day operations. Following a dispute between the Dobbin Group and the City of St. John's over the use of Mile One Centre, the Fog Devils nonetheless secured a lease for the stadium under the Dobbin group.

The Fog Devils did not achieve the degree of financial success or the attendance of the SJML, necessary to ensure long term sustainability, which was attributable to a number of factors. First, there was little recognition or association with the team name of Fog Devils. The name may not have been well researched or thought out. While it may have had appeal to a much younger crowd, it did not appeal to the 
more traditional hockey fan. Season ticket sales plummeted after the first season and continued to erode in the subsequent third and final seasons.

Second, the Dobbin family, while being well connected and part of the St. John's business community, were not particularly well experienced in the administration of a hockey franchise. Moreover, they did not retain some of the key management personnel from the SJML era who had the greatest experience in making that franchise successful. In particular, one key person relocated out of the province, being lured away by another sporting organization that paid a premium amount for the expertise that he had acquired.

Third, there was a widely held belief in St. John's that the AHL was a step away from the NHL and that the QMJHL was neither as good a product nor as entertaining as the AHL. While the QMJHL had flourished in the other three provinces in Atlantic Canada, collectively known as the Maritimes, the successes of these franchises could be better explained through very close rivalries with other teams in the area and the success of Maritime-based teams, which have won not only the QMJHL championship, but also the Memorial Cup, the national Major Junior A championship. The Memorial Cup was won by Saint John in 2011, Halifax in 2013, and Acadie-Bathurst in 2018.

Fourth, in the Maritimes, there was already a strong Junior A market before the introduction of the QMJHL into the Maritime region, The region had already developed regional rivalries, and their close proximity allowed teams to travel via bus, a much less expensive option than was available to the only Newfoundland team in the QMJHL, which required air transportation. Travel by bus to St. John's was not a viable option for competing teams. There is a six-hour ferry ride to the island of Newfoundland from the most easterly point in Nova Scotia and then a $900 \mathrm{~km}(540 \mathrm{mi})$ drive to St. John's, which is at the opposite end of the island from the ferry terminal. The expensive airfare to reach St. John's was the only option.

Fifth, the introduction of the Major Junior A from Junior was perceived as a step upward from Junior A in the Maritimes, whereas it was seen as a step down from the AHL by the St. John's market.

Sixth, in summary, there were significant differences between the market in St. John's, where the AHL has been strongly preferred and the Maritimes where Major Junior A hockey was preferred. Moreover, the Maritimes were much less interested in the AHL, as evidenced by all the previous AHL teams having folded or been relocated.

On the ice, the Fog Devils made the playoffs in each of their three seasons. In the inaugural season of 2016-17, despite a losing regular season record of 30-34-5-1, they made the playoffs, but lost in the first round to Cape Breton in five games. In the second year of 2006-07, they again made the playoffs, but had a worse record, 28-36-4-2. They were swept by Cape Breton. In the 2007-08 season, they produced their best season with a 32-30-1-7 record, but again lost in the first round to Acadie-Bathurst 4-2.

Overall, the Fog Devils would have reasonably good crowds at the start of each season, which then dwindled as the season progressed. The team continually failed to produce either a winning season or a significant number of playoff victories, record 3-12 in the playoffs.

In December 2007, the Fog Devils President, Brad Dobbin, announced that the team was in financial trouble having lost $\$ 750,000$ during the second season and noted that the team was experiencing another season of declining attendance.

On January 22, 2008, the Fog Devils team was sold to Montreal businessman Farrell Miller. This announcement was made official at a press conference on March 10, 2008, which confirmed the relocation of the Fog Devils to now be known as the Montreal Junior Hockey Club to play in the Verdun Auditorium. This action was not unlike the NHL strategy of co-locating their AHL franchises in cities close to the parent club.

As a result of the sale of the Fog Devils, the province of Newfoundland and Labrador became the only Canadian province without a Canadian Hockey League (CHL) franchise. Again the fire may have been extinguished, but the quest for a franchise would again be rekindled. In 2011, following a three-year gap in hockey and a six year gap in AHL hockey, St. John's would again obtain another franchise when the St. John's Ice Caps, the AHL affiliate of the Winnipeg Jets, began play in the AHL. 


\section{THE ST. JOHN'S ICECAPS 2011-17}

In 2011, exactly 20 years after the AHL first came to St. John's, the AHL returned to St. John's. Once again it was as a franchise searching for a home, exactly like the Newmarket Saints in 1991 when they became the SJML. This time the Manitoba Moose relocated to become the St. John's IceCaps.

This franchise was founded in 1994 as the Minnesota Moose, a team in the former International Hockey League (IHL). The team initially played two seasons in St. Paul, Minnesota before relocating to Winnipeg in 1996. This action was undertaken to fill the void that developed when the original Winnipeg Jets (1972-96) relocated from Winnipeg to Phoenix, AZ. The Moose continued to play in the IHL until the league ceased operations. At that time, the Moose joined the AHL and became the farm team for the Vancouver Canucks.

The owners of the Moose franchise, True North Sports and Entertainment, purchased the Atlanta Thrashers of the NHL in May 2011 and relocated them to Winnipeg for the 2011-12 season. As True North faced a conflict with owning both an AHL franchise and an NHL franchise, they ended their AHL affiliation with the Canucks. The Canucks then affiliated with the Thrashers' former AHL-affiliate, the Chicago Wolves. With the return of the NHL to Winnipeg a new venue was required for the Moose. A deal was negotiated with Danny Williams, the former Premier of Newfoundland and Labrador. An astute businessperson, Williams had previously amassed a fortune in divesting his cable television business, to Rogers Cable. The AHL Board of Governors unanimously approved the relocation of the franchise to St. John's on June 20, 2011. Later that day Williams and True North's Senior Vice President, Craig Heisinger, held a kickoff event at Mile One Stadium announcing the relocation of the franchise.

The news of the relocation was greeted with great enthusiasm by the sporting community. The choice of the name was of great interest. Williams had stated that he would have liked to have held a fan contest to name the team, but this was impractical given the short time line before the beginning of the season. Consequently, the task was brought to the team's advisory committee. The franchise could easily have been known as either the Newfoundland Moose or the St. John's Moose, as moose and moose hunting are popular in the province. There is even a song Gotta get me moose b'y sung by the local popular group Buddy Wasisname and the Other Fellers about moose hunting. However, there are also a number of traffic accidents involving moose with vehicles. Moreover, the requirement for brand recognition was that the name should reflect a St. John's icon. In the former Newfoundland Senior Hockey League, the St. John's team was known as The Capitals, given that St. John's is the capital city of the province. So using Capital in the name was a return to the roots of hockey in the province. Ice is considered a strength and so to put IceCaps together was very natural. It also helped that Tim Horton's, the leading national coffee chain in Canada, had a very popular product known as the Iced Capp, which helped with brand recognition. It was solely an unanticipated, ancillary benefit, not intended as a copyright infringement.

The team uniforms for the St. John's IceCaps, under the Winnipeg Jets, were patterned after the parent club: aviator blue, white, polar night blue, and silver. The jerseys included the Jets' primary logo on the shoulder. Later, when the franchise became affiliated with the Montreal Canadiens, the uniforms reflected the traditional red, white, and blue of the Canadiens.

The IceCaps logo was the same for both franchises, albeit with different color schemes to match the respective uniforms of the two parent clubs. The St. John's IceCaps logo is a registered trademark of the Danny Williams group, but neither the Jets nor the Canadiens. Accordingly, it could conceivably be used for any future incarnations of the IceCaps in St. John's.

The launch of the season ticket campaign was a great success. Fans could purchase a three-year commitment to the team by paying $\$ 150$ (three years@ @ \$50 per year) and be guaranteed their chosen seats for that three-year period. Once again, team officials used the same market factor analysis process and considered the same market factors that they used in assessing potential demand for season tickets in the early days of the SJML, 20 years earlier. However, by this time the population of the SJCMA had risen to 215,000 and the Newfoundland economy, buoyed by developments in the burgeoning offshore oil industry, afforded significantly higher corporate sponsorship potential than was the case with the first AHL franchise in 1991. Using the same market factors previously employed, including: interest in 
professional sports, ability and willingness to pay for season tickets and population size (residential and corporate), the following market potential analysis for sustainability of the franchise was developed.

1. Market factor 1: Interest in professional sports, estimated at $20 \%$ of the population;

2. Market factor 2: Ability to pay for 2 seasons tickets, estimated at $20 \%$ of the population;

3. Market factor 3: Population base aged 25-70 $(150,000)$.

From this analysis, the estimated market potential for season ticket holders was:

$$
\text { Market Factor } 1(20 \%) \times \text { Market Factor } 2(20 \%) \times \text { Target Population Base }(150,000)=6,000 \text {. }
$$

With this estimate and comfortable in the knowledge that the economy would continue to be strong for the foreseeable future, the operating decision at the time was for Williams and his partner, former SJML executive Glenn Stanford, to decide what proportion of the seating capacity would be held by season ticket holders and what proportion would be left for sale to the general public. On the one hand, having as many tickets as possible in the hands of season ticket holders would serve to maximize profitability. On the other hand, doing so would mean that fewer tickets would be available for the average hockey fan, who, while loving hockey, might not be able to afford a full season ticket package. Convinced that overall demand was high, the owners went with a model to have $70 \%$ of the 6,287 seats available to season ticket holders, with another $10-20 \%$ available for 5,10 or 20 game packages and the remaining 1,000 seats available to the general public, via general sale, which satisfied last minute online sales or walk up demand for tickets.

From the outset the market analysis proved to be reasonably accurate. In fact, the IceCaps had 146 consecutive sellouts and together with excellent support from a core group of corporate sponsorships, which also had been strong under the SJML, but dwindled under the Fog Devils, the team had very strong financial and on-ice success. In 2013-14 they went to the Calder Cup finals, losing on home ice to the Texas Stars, the affiliate of the Dallas Stars. The 1991-92 SJML, had also lost the Calder Cup on home ice.

Overall, this team's on-ice performance was on par with the SJML. In the inaugural season of 201112, the IceCaps finished in first place in the Atlantic division and reached the Eastern Conference Championship series, but were swept in four games by the Norfolk Admirals, the eventual Calder Cup winners. After failing to make the playoffs in their second season, the IceCaps finished in second place in the Atlantic Division. Following wins in three playoff series against Albany Devils, Norfolk Admirals, and Wilkes Barre Scranton Penguins, the IceCaps claimed the Richard Canning Trophy as the Eastern Conference champions and advanced to the Calder Cup finals against the Texas Stars.

In January 2014, True North Sports, the holding corporation for the Winnipeg Jets confirmed that they were exploring plans to relocate their AHL franchise to Thunder Bay, Ontario after the lease with the Williams Group expired in 2015. Despite being an on-ice and financial success, the location of St. John's presented significant travel difficulties for Jets' personnel, as well as for AHL teams travelling to St. John's. These were the same reasons given in 2005 for the relocation of the SJML to Toronto.

The ever-popular Danny Williams stated that he would try to find another AHL team in the event that the IceCaps were to leave. In September 2014, Williams and True North agreed to extend the agreement for one additional year through the 2015-16 season. However, the initial three-year period of season tickets had concluded and non-renewal for the fourth year showed signs of slippage.

A year after the September 2014 agreement, a deal was struck between Williams, True North and the Montreal Canadiens for their AHL affiliate, the Hamilton Bulldogs, to relocate to St. John's for 2015-16, following the move of the Moose back to Winnipeg. The Bulldogs then became the IceCaps. This deal was expected to be temporary as the Canadiens, like the Jets, owned the AHL franchise and had already planned to locate their AHL closer to the NHL parent. In July 2016, the Canadiens confirmed the relocation of their AHL team to the newly constructed Place Bell Arena in Laval, Quebec for the 2017-18 season. So, St. John's had the distinction of having had three Canadian NHL teams pull their AHL affiliates from St. John's, in spite of the viability of the franchises, in part to reduce travel costs, but primarily to have their primary development team play closer to the parent club. 
Once again, Williams stated his intentions to find another franchise with the AHL or another league. Williams fanned the quest for yet another hockey franchise. There was, however, a lapse of a year when St. John's did not have a hockey team playing in Mile One Centre during the 2017-18 season. However, the National Basketball League of Canada granted a franchise to St. John's in the interim. Known as the St. John`s Edge, the team began playing at Mile One Stadium in 2017-18 and has been very successful in its first two seasons. In 2018, the ECHL approved the expansion Newfoundland Growlers to begin play for the 2018-19 season.

\section{THE NEWFOUNDLAND GROWLERS 2018-ON GOING}

The Newfoundland Growlers are a minor league hockey club based in Mile One Centre in St. John's. The team began play in the ECHL at the start of the 2018-19 hockey season. The ECHL (formerly known as the East Coast Hockey League, but now known solely by its initials ECHL) is a mid-level professional hockey league based in Princeton, New Jersey. The league is one tier below the AHL. With 27 teams in the league, including 25 in the United States and 2 in Canada, the ECHL is currently in the process of repositioning itself as the second tier development alternative for the NHL and its affiliated AHL teams, particularly those teams that have sufficient player depth to allow for early stage development at the ECHL level. This fact was reiterated on May 16, 2019 by Toronto. Leafs General Manager Kyle Dubas, when interviewed in St. Johns, spoke of the early success of the Newfoundland Growlers (Toronto's ECHL affiliate) and indicated Toronto's intent to use their partnership with the Growlers to ensure that young talent in the Toronto development system received a good start in professional hockey by playing for the Growlers first, then the Marlies, and finally with the big club the Toronto Maple Leafs. In terms of baseball nomenclature, the AHL would correspond to AAA, whereas the ECHL would be AA.

Both the AHL and the ECHL are the only minor leagues recognized by the collective bargaining agreement between the NHL and the National Hockey League Players' Association, meaning any player signed to an entry-level NHL contract and designated for assignment must report to a club in either the AHL or the ECHL. The ECHL's players are represented by the Professional Hockey Players' Association. It must be noted that 623 players have played at least one game in both the ECHL and the NHL, thereby discharging the ECHL's responsibility as a developmental league. While players can go directly from the ECHL to the NHL more often than not players go to the AHL and then onto the NHL.

The relationship between the ECHL and the NHL is not as strong as the relationship between the NHL and the AHL. As of March 28, 2019, of the 26 players on the Growlers' roster, 13 were under contract to the Marlies, 11 to the Growlers and only 2 to the parent Leafs. For the 2018-19 season, 25 of the 31 NHL teams had affiliates in the ECHL. No ECHL affiliates were with the Anaheim Ducks, Columbus Blue Jackets, Florida Panthers, Montreal Canadiens, Nashville Predators and the San Jose Sharks. Two independent teams play in the league, Greenville Swamp Rabbits and Rapid City Rush. Unaffiliated NHL teams lend players under contract to ECHL teams for development and increased playing time. The league's regular season schedule mimics the schedules of both the AHL and the NHL, beginning the season in October and finishing in April. The playoffs for the Kelly Cup then begin. The 2017-18 champions, the Colorado Eagles, left the ECHL to play in the AHL, as the affiliate of the Colorado Avalanche.

Although Williams had stated his intention to bring a hockey team back to St. John's, two rival groups formed to contest for a franchise. The first group was the operators of the St. John's Edge, the basketball franchise which began play in 2017 in Mile One Centre and was then its primary tenant. The Edge looked to secure a QMJHL franchise. The other group was local businesspeople, including Glenn Stanford, who sought to secure an ECHL franchise.

The ECHL franchise was conditionally approved for the Stanford group pending an agreement to use the Mile One Centre facility. The deal was delayed until late 2018 after a dispute with the St. John's Edge over which group had rights to Mile One went to arbitration. After the leasing rights were settled, the ECHL officially approved the application from the Stanford group on March 13, 2018 to play in the North Division of the Eastern Conference. This group also successfully negotiated a partnership with the 
Toronto Maple Leafs, which was announced on June 14, 2018. Among the names considered for the new franchise were the Shamrocks, Storm, Regiment, and the eventual choice the Newfoundland Growlers. The team name was announced on May 22, 2018. The reference was to the Newfoundland Dog, in general, and to Sable Chief, in particular. Sable Chief had been the mascot of the Royal Newfoundland Regiment during World War One.

Ryane Clowe, a Newfoundland native, previously an assistant coach with the New Jersey Devils was named head coach on June $20^{\text {th }}$. John Snowden was named Assistant Coach on July $19^{\text {th }}$, having served in the same capacity for the Orlando Solar Bears, the Leafs' previous ECHL affiliate. The Growlers played their first home game in front of a sold-out crowd on October 12, 2018 in a 3-2 win over the Florida Everblades. In attendance was Buddy, the mascot for both the SJML and the IceCaps. With the return of hockey to St. John's and the sell out for the opening night, the franchise was expecting great success, but this proved not to entirely be the case. In January 2019, Coach Clowe stepped down citing health concerns and was replaced by Assistant Coach Snowden.

In terms of attendance the Growlers finished their first year in the ECHL with an average attendance of 3,784 ranking them $18^{\text {th }}$ of the 27 teams in the league. With an average attendance that ranged from 2,265 to 7,932 and an overall league average of 4,445, the team underperformed the league in its first year's attendance. That said, Toronto GM Kyle Dubas, noted after visiting the franchise in May 2019 that he was very pleased with the development to date, suggesting that he expected attendance to grow as the team continued to succeed on the ice. By comparison the St. John's Edge basketball team drew an average crowd of 3,464. While attendance for the Edge was lower than the Growlers, the Edge had the best attendance in the 10-team basketball league; close rivals in Halifax and Moncton drew 1,779 and 1,011 average attendance, respectively. The basketball league has a salary cap of $\$ 150,000 \mathrm{CDN}$, while in the ECHL contracts are denominated in USD. Moreover, basketball teams carry fewer players and do not have as much equipment to transport. The equipment in basketball is also much lighter. Accordingly, the basketball franchise incurs less cost for the team.

As it stands following completion of the first season, the Newfoundland Growlers enjoyed the greatest possible success on ice that they could have by capturing the Kelly Cup in their inaugural season, but did not have the financial success of either the St. John's Maple Leafs or the IceCaps given the light attendance for most of the season. However, it remains to be seen for the second season if the attendance will pick up to ensure profitability and long term sustainability. Costs might also increase as the Manchester Monarchs, the closest ECHL team to St. John's, folded following the 2018-19 season. Has the quest for a hockey franchise ceased or is St. John's destined to look further?

\section{CONCLUSIONS}

The research and collective experience suggest that there are many factors to consider, when pursuing a minor league professional sports franchise. Unfortunately, not all these factors are within the control of a prospective franchise holder. For example, the approach to player development which a parent club (and the league in which it operates) takes at the outset of any development contract may change significantly as this relationship unfolds. The enhancement of a player's professional development is at the heart of most franchise agreements for the parent club. Given that many municipalities and their private sector partners invest significant funds in order to accommodate the needs of the parent club, and assuming that these funds will very often have to be amortized over many years, the assumption that the terms of a development agreement will not change, or that one party or the other will not want to renegotiate them, is naïve. In fact the inevitability of such change is likely the reason that most NHL-AHL development agreements are initially negotiated for five years or less. At the same time, many municipal financing agreements in support of such arrangements often endure well beyond the initial terms of the agreement.

Consider, for example, the Belleville Senators and the City of Belleville, Ontario, which recently signed an AHL development agreement with the Ottawa Senators of the NHL. Belleville, with a population of 50,700, approved expenditures of \$20,000,000 for upgrades to Yardman Arena in order to accommodate the Senators' developmental team plan. With this new investment, seating capacity at 
Yardman Arena would increase to 4,400. Even if these funds were to be amortized over 20 years (a number which far exceeds the life cycle of a typical AHL affiliation agreement), this would mean that the team would need to generate an additional $\$ 1,000,000$ in annual net income simply to recoup the leasehold improvement costs at Yardmen Arena, a daunting task. Belleville's 2018-19 attendance averaged 3,600 per game, one of the five lowest average attendance in the AHL.

Using the market factors previously outlined, one would have expected a season ticket base in Belleville of approximately 2,800 (35,000 people aged 25-64 in Belleville $\times 20 \%$ interest $\times 20 \%$ ability to pay $=1,400$ season ticket holders $\times 2$ tickets each $=2,800$ ). Assuming a game day walk-up attendance of 800 to 1,000 , the model would predict average attendance of 3,600 to 3,800 , a range quite close to Belleville's actual attendance of 3,589. While Senators GM Randy Lee was recently quoted as saying that first-year attendance in Belleville was, on average, only 800 below capacity, the reality is that even if the Belleville Senators were to achieve sell out capacity on a regular basis, they would still be below the attendance number generally considered necessary to ensure franchise stability, which would be around 5,000 , depending on ticket prices, travel costs, annual franchise fees to the parent.

Of course, there are other ancillary reasons why municipalities decide to commit relatively large amounts of money to support new municipal infrastructure or the enhancement of existing municipal buildings, such as the Yardman Arena in Belleville. These reasons include the desire to attract high profile music concerts, conventions, trade shows and a host of other activities designed to increase revenues and otherwise improve the livability and attractiveness of their respective cities and towns. In any such decisions, municipal administrators and private investors should also consider the direct and indirect economic benefits associated with such construction projects and the ongoing benefits associated with enhanced entertainment and exhibition space. Locke (2006) concluded that the economic impacts from construction, operations and other activities associated with Mile One Centre and the St. John's Convention Centre, with a completed cost of $\$ 51,000,000$, were significant.

For example, during the five-year construction period for these integrated facilities, more than 3,000 full-time equivalent jobs, and nearly $\$ 120$ million in GDP/income was generated within the Census Metropolitan Area of St. John's. The corresponding estimates for the province of Newfoundland and Labrador included 3,300 person-years of employment and \$130 million in GDP/income. The amount of provincial and federal taxes generated over this period were $\$ 12$ million federally and $\$ 13$ million provincially. Expressed on an average annual basis, these facilities support or create approximately 500 person-years of employment per year and approximately $\$ 20$ million in income benefits to local workers and businesses. In addition to the direct and indirect economic benefits associated with such projects, Locke (2006) also noted the significant number of induced jobs that were created in support of ongoing activities at Mile One Centre and the St. John's Convention Centre. For municipal administrators or politicians contemplating such investment(s), there is more to such decisions than might seem obvious on the surface.

Beyond the financial considerations, the collective experience of the authors of this study suggest that there is a variety of other qualitative considerations that can also serve to affect the stability and longevity of such development agreements. First, the commitment which the parent club has to the community and their belief that 'your city' is a 'good place' for their developing players to play.

Second, the collective belief by the parent club in the wisdom of long-term player development is important. Typically referenced by their stated desire to not rush a players' development. This statement has typically meant longer periods for younger players at the AHL and more recently ECHL levels.

Third, the stated commitment by the parent club to put a winning team on the ice at the AHL and ECHL levels. As noted earlier, the correlation between on-ice performance and off-ice financial performance is quite high. Having a parent club that is committed to the success of its developmental team is essential to the longer term success of both franchises. As of 2018-19, the ECHL Growlers had 12 AHL prospects on their affiliated ECHL team, a number that is significantly higher than other NHL teams make available and undoubtedly a reason for the teams' early on-ice success.

Fourth, divisional and conference alignment, while not being directly under the control of the AHL club or its NHL parent, can often be negotiated at the outset of such an agreement, as the AHL Board of 
Governors ultimately has to approve where any new franchise is placed, including decisions related to divisional alignment. Being placed in a geographically dispersed division can increase travel costs, wear and tear on players and perhaps most importantly for the parent club, can impact the number of practice days that are available throughout the 76 game schedule encompassing six-months of the ECHL. This latter point is of particular importance to the parent club as one of the primary concerns is that any player that is 'called up' to the parent NHL club, is able to step up and fit in to the system of on-ice play which the parent club is using. In our experience this is one of the primary reasons why the Leafs (and other NHL clubs) decided to co-locate or closely locate their AHL affiliates within close proximity to their parent $\operatorname{club}(\mathrm{s})$.

Finally, there is something to be said for the overall fit between the two organizations that are party to such development agreements, the local ownership group and the parent club ownership. In the authors' experience, it is only when times are tough and the affiliate club needs help, that one really know what kind of relationship one has with the parent club. When support comes in such situations, typically in the form of additional player support and parent- club supervision of on-ice activities at the AHL team site, only then will one know what kind of relationship one has with the parent-club. NHL parent commitment, in the form of player supervision and scouting and player support are some of the most important dimensions of support at the AHL level, as evidenced by the experience in St. John's, with the Toronto Maple Leafs, the Winnipeg Jets and the Montreal Canadiens.

There are also a number of important considerations for the parent club when considering such player development agreements/relationships. Beyond the obvious revenue and expense considerations, from the franchisor's perspective, other important aspects of a player development agreement include: the quality of the facility in which games are to be played (upgrades to or new arenas can be part of any franchise agreement); the availability of a quality practice facility in the event that the main facility is not available; the overall availability of practice time; the quality off-ice facilities and equipment for training and rehabilitation; the quality of medical care/allied health professions in the immediate area; and the quality of player accommodations.

In short, once a prospective minor league affiliate progresses beyond the obvious revenue and expense considerations, there are many other factors that can influence the affiliate location decision, not all of which may be obvious to the parties in the negotiating phase, which may mean information asymmetries and therefore moral hazards in negotiation. Overall, franchisors are seeking all the factors that can positively affect a player's development and his experience while on a development team. Once these are in place, the franchisor is more likely to be confident that in all aspects of a player's hockey development, from the style of play to overall maturity. Only then will he be able to rise to the next level in his playing career and make the kind of impact that warrants the significant financial investment being made by the parent club in player development. While the revenue and expense aspects of such affiliation agreements are important, it is unlikely that they will be the key differentiating factors in the signing of such agreements. While all these conditions are necessary, they are not sufficient to ensure that a prospective franchisee will be able in the quest to successfully negotiate a long-term agreement with an NHL/AHL partner. St. John's has had three unsuccessful quests for a hockey franchise. Only time will tell if the fourth quest for a franchise will be successful. The fire is strong at the moment but fires, as has been seen, can be extinguished.

\section{REFERENCES}

A Brand-new hockey game at Mile One in St. John's. (2017, December 7). The Telegram. AHL team closer to coming to St. John's. (2011, June 1) Canadian Broadcasting Corporation.

American Hockey League. (n.d.). Retrieved from https://en.wikipedia.org/wiki/American_Hockey_League

Baby Buds move to Toronto. (2011, October 15). The Telegram.

Ballard wants Leafs to have own farm club. (1980, March 21). The Globe and Mail.

Board of Governors Approves Changes for 2018-19 Season. (2018, March 13). ECHL. 
Campbell, N. (1982, June 3). Fans fail to save Hawks. The Globe and Mail.

Campbell, N. (1982, July 6). AHL rejects shift of Leaf farm club. The Globe and Mail.

Canadiens moving AHL affiliate to Laval in 17-18. (2016, July 11). AHL.

Dryden, K. (1983). The Game. John Wiley \& Sons: Toronto.

ECHL. (n.d.). Retrieved from https://en.wikipedia.org/wiki/ECHL

ECL | Premier "AA” Hockey League. (n.d.). Retrieved from https://www.echl.com

Houston, W. (1982, June 8). Ballard stymies Canadian division. The Globe and Mail.

IceCaps Seek New Hockey Partner. (2016, July 11). Our Sports Central.

Jets Exploring Move of AHL Team from St. John's to Thunder Bay. (2014, January 21). TSN.

Jets keeping AHL IceCaps team in St. John's. (2014, September 3). The Hamilton Spectator.

Leaf team to leave Moncton. (1982, June 2). Toronto Star.

Leafs get new farm club in Central Hockey League. (1981, June 24). The Globe and Mail.

Leafs, Hawks to Moncton. (1978, June 6). Toronto Star.

Leafs place AHL team in St. Kitts. (1982, June 22). The Globe and Mail.

Locke, W., Goulding, S., Elton, K-J., \& Marcel. (2006, October). The Economic Impacts of Mile One Centre and the St. John's Convention Centre.

MacCarl, N. (1966, July 7). Sale of Rochester hockey team pads Maple Leafs coffers. Toronto Star.

MacEachern, D. (2016, November 3). Running on empty: Once the hottest ticket in St. John's, IceCaps facing rows of empty seats. CBC News.

McCarthy, B. (2017, April 28). That's it folks; IceCaps are done and so is the AHL in St. John's. The Telegram.

Montreal Canadiens' farm team relocating to St. John's next season. (2015, March 12). The Compass.

Moose to Lose Name in St. John's Due to Animal's Deadly Past. (2011, July 30). The Canadian Press.

National Basketball League of Canada. (n.d.). Retrieved from https://en.wikipedia.org/wiki/National_Basketball_League_of_Canada

National Basketball League of Canada. (n.d.). Retrieved from http://nblcanada.ca/landing/index

New Brunswick Hawks. (n.d.). Retrieved from https://en.wikipedia.org/wiki/New_Brunswick_Hawks

Newfoundland Growlers Announce Affiliation with Toronto Maple Leafs \& Toronto Marlies. (2018, June 16). The Newfoundland Herald.

Newfoundland Growlers looks to be the name of choice for new ECHL team. (2018, April 26). The Telegram.

Newfoundland Growlers. (n.d.). Retrieved from https://en.wikipedia.org/wiki/Newfoundland_Growlers

Pro hockey returning to St. John's. (2011, June 10). Canadian Broadcasting Corporation.

Quebec Major Junior Hockey League. (n.d.). Retrieved from

https://en.wikipedia.org/wiki/Quebec_Major_Junior_Hockey_League

Rochester Americans. (n.d.). Retrieved from https://en.wikipedia.org/wiki/Rochester_Americans

Rochester makes it-Gains AHL franchise. (1956, July 3). Toronto Star.

Sabres settle dispute with Leafs. (1982, July 23). Montreal Gazette.

Sabres won't oppose move. (1982, July 23). The Observer.

Securing of ECHL Team on Hold During Arbitration: MacDonald. (2018, January 30). VOCM-FM.

Short, R. (2011, October 22). Game melts away for IceCaps. The Telegram.

St. John's Edge. (n.d.). Retrieved from https://sjnbl.prestosports.com/landing/index

St. John's Fog Devils. (n.d.). Retrieved from https://en.wikipedia.org/wiki/St._John\%27s_Fog_Devils

St. John's IceCaps. (n.d.). Retrieved from https://en.wikipedia.org/wiki/St._John\%27s_IceCaps

St. John's Maple Leafs. (n.d.). Retrieved from https://en.wikipedia.org/wiki/St._John\%27s_Maple_Leafs

The American Hockey. (n.d.). Retrieved from League https://theahl.com/

The Edge. (n.d.). Retrieved from https://en.wikipedia.org/wiki/The_Edge

Toronto Maple Leafs. (n.d.). Retrieved from https://en.wikipedia.org/wiki/Toronto Maple Leafs

Williams behind new AHL team for St. John's. (2011, May 21). The Telegram. 